\title{
COMUNIDAD Y APROPIACIÓN ORIGINARIA EN LOS TRATADOS SOBRE EL GOBIERNO CIVIL DE LOCKE
}

\section{COMMUNITY AND ORIGINAL APPROPRIATION ON LOCKE'S TWO TREATISES OF GOVERNMENT}

\section{Felipe Schwember Augier ${ }^{*}$}

\begin{abstract}
RESUMEN: El tipo de comunidad originaria de bienes del que parte una teoría histórica de la justicia es crucial para su comprensión y su viabilidad. Pese a ello, Locke no ofrece una explicación clara y unívoca de esta cuestión al tratar el problema de la propiedad. En el presente trabajo se intentará dilucidar el tipo particular de comunidad del que parte Locke. Se argüirá que, a partir de las razones que ofrece para desechar el origen convencional de la propiedad, así como de los requisitos que exige a las apropiaciones originales, es posible atribuir a Locke alguna forma débil de comunidad originaria positiva de bienes.
\end{abstract}

Palabras clave: Locke, propiedad, comunidad originaria, iusnaturalismo.

ABSTRACT: The type of original community of goods that is on the basis of a historical theory of justice is crucial for the understanding and viability of such theory. Nevertheless, Locke does not offer a clear and unambiguous explanation on this issue when treating the problem of property. In this work I try to elucidate the particular type of community that Locke has as basis of his theory of property. I will hold that, taking into account the Lockean arguments against the contractarian origin of private property as well as the Lockean requirement for the originals acquisitions, it is possible to claim that there is a certain kind of weak positive original community in Locke's natural law theory.

Key words: Locke, property, original community, natural law.

\section{INTRODUCCIÓN}

Uno de los propósitos declarados de Locke en el Segundo Tratado es ofrecer una explicación no convencional del origen de la propiedad (II, \$25, 16-19) ${ }^{1}$. En rigor, el resultado de este intento no puede juzgarse al margen del problema de la situación inicial de los bienes (en un comienzo ¡todo es de todos o nada es de nadie?), pues los diferentes

\footnotetext{
Felipe Schwember Augier, Licenciado en Derecho por la Universidad Católica de Chile. Licenciatura en Filosofía Pontificia Universidad Católica de Chile. Dr. en Filosofía por la Universidad de Navarra. Profesor del Centro de Investigación en Teoría Social y Política de la Escuela de Gobierno, Universidad Adolfo Ibánez. Dirección: Diagonal Las Torres 2640, Peñalolén, Chile. Correo electrónico: felipe.schwember@uai.cl; teléfono: 23311675. Agradezco a los evaluadores anónimos de la Revista Chilena de Derecho sus comentarios, sugerencias y correcciones.

1 Los Tratados de Locke se citan indicando con números romanos si se trata del Primer o del Segundo Tratado, respectivamente. Luego en arábigos se indica el párrafo y la(s) línea(s) del pasaje que se cita. Otro tanto vale para las citas de Grocio y Pufendorf: se indica primero en romanos el tomo o libro y luego en arábigos el parágrafo y la(s) línea(s) de la cita. Las referencias a la Suma Teológica de Tomás de Aquino (abreviada "ST.") o a la obra De iure et iustitia (abreviada en lo sucesivo como "DII") de Domingo de Soto se hacen del modo acostumbrado.
} 
modos de representarse dicha situación inciden en las condiciones que debe satisfacer una apropiación unilateral para poder ser considerada como lícita. De hecho, bajo algunas descripciones de la situación inicial de los bienes (llamada comúnmente "comunidad originaria de bienes"), una apropiación unilateral no es en absoluto posible. Por tanto, para una teoría histórica de la justicia, como la de Locke, la dilucidación de este problema resulta crucial. Lamentablemente, Locke no es todo lo explícito que pudiera quererse con respecto a este sensible punto. De hecho, como afirma Buckle, parece que Locke ni siquiera es capaz de percibir la importancia que tiene la distinción entre una comunidad originaria positiva y una comunidad originaria negativa ${ }^{2}$. En el presente trabajo se intentará hacer una reconstrucción del concepto de comunidad originaria del que Locke parte en su teoría de la propiedad. Para ello, en primer lugar, se intentará fijar los términos del problema distinguiendo cuatro posibles puntos de partida para toda teoría histórica de la propiedad (i.e., distintas formas de comunidad originaria). En seguida se repasará brevemente la objeción de Filmer a las teorías iusnaturalistas prelockeanas de la propiedad. Esta crítica de Filmer es importante no porque constituya una objeción de peso a las teorías iusnaturalistas prelockeanas de la propiedad sino porque fijó para Locke las coordenadas principales del problema del origen y justificación de la apropiación privada.

Una vez situado en términos generales el contexto de la discusión y el modo en que Locke la interpretó, se procurará dilucidar el punto de partida de la teoría lockeana de la propiedad. El establecimiento de dicho punto de partida se intentará fijar por medio de una suerte de reconstrucción retrospectiva: la hipótesis que mejor calza con el propósito y la argumentación general de Locke en favor de la propiedad es aquella que debe adoptarse como descripción de la situación inicial de los bienes. A este respecto, resultan particularmente importantes, primero el argumento dialéctico que Locke formula en el \$25 del Segundo Tratado en contra de la posibilidad de que en un principio los bienes sean poseídos in solidum y, segundo, el hecho de que Locke sujete las condiciones la validez de las apropiaciones unilaterales al cumplimiento de ciertas condiciones que tienen por finalidad salvar los derechos de terceros (cláusulas lockeanas). Se sostendrá que la consideración conjunta del argumento dialéctico y de las cláusulas lockeanas permite desechar al menos dos de las cuatro posibles hipótesis iniciales respecto del estado originario de los bienes.

Se argüirá, en fin, que para despejar el problema del tipo de comunidad originaria del que parte Locke, no basta con examinar su tratamiento de las apropiaciones originarias sino que además es necesario atender al derecho al excedente que Locke incluye en favor de los desposeídos en el Primer Tratado. Se intentará demostrar que este derecho, que es común a toda la tradición iusnaturalista prelockeana y que es reflejo de un derecho natural de uso, es compatible únicamente con un tipo particular de comunidad originaria que aquí llamaremos comunidad originaria positiva simplemente conjunta. Con ello se espera demostrar, por consiguiente, que es esa y no otra el tipo de comunidad originaria del que parte Locke en su teoría de la propiedad. En apoyo de esta conclusión se ofrecerá, en fin, un argumento ulterior con el que se espera demostrar la conveniencia de desechar las otras formas de comunidad originaria positiva, no solo con vistas a la comprensión de la teoría 
lockeana de la propiedad, sino con vistas a la formulación de cualquier teoría histórica razonable de la propiedad.

\section{PRINCIPIOS HISTÓRICOS DE DISTRIBUCIÓN DE BIENES}

De acuerdo con la nomenclatura que ofrece Nozick en "Anarquía, Estado y utopía”, puede afirmarse que, grosso modo, los intentos de justificación de la propiedad apelan o a principios históricos o a principios de resultado final ${ }^{3}$. Como lo indica su nombre, para las teorías que adoptan los primeros, la licitud de la posesión de los bienes dependerá de cómo estos han llegado a nuestras manos. Para una teoría de resultado final, en cambio, la distribución será lícita si es que se ajusta a un determinado estado o resultado establecido de antemano. Como afirma Nozick, "[d]e acuerdo con un principio de justicia distributiva de porciones actuales, lo único que se necesita tomar en cuenta, al juzgar la justicia de una distribución es: quién termina con qué” ${ }^{4}$.

Las teorías históricas descansan en una intuición moral fundamental: que no es justo intentar determinar a partir únicamente de principios a priori qué es lo que corresponde a cada cual. Así, para una teoría histórica, ningún criterio de justicia puede pretender determinar qué es lo suyo de cada uno de espaldas a lo que cada uno ha hecho. Para saber si B debe estar en posesión exclusiva o no del bien X, yo necesariamente debo considerar qué es lo que B ha hecho para llegar a tener en su poder ese bien. Por consiguiente, para un defensor de las teorías históricas, conocer el estado actual de la distribución de bienes en el mundo con prescindencia del modo en que se ha llegado a dicho estado no sirve para determinar la forma en que han de distribuirse los bienes. Por el contrario, atribuir los bienes a partir de un principio de resultado final (por ejemplo, la mayor cantidad de felicidad neta en el mundo) y con independencia de lo que cada cual ha hecho es, desde el punto de vista de una teoría histórica, injusto.

Ahora bien, en concordancia con su principio subyacente, una teoría histórica entiende que la posesión de un determinado bien solo se convertirá en propiedad si y solo si dicha posesión tiene su origen en un título legítimo (supongamos, la compraventa o la permuta) y no en un acto violento o vicioso (como el robo, el hurto, etc.). A su vez, aquel de quien yo obtengo el bien debe haber tenido un título legítimo, pues de lo contrario, la transferencia que él me hace del bien no permite que yo adquiera la propiedad. Y este a su vez debe haberlo adquirido de otro que tenía un título legítimo, y así sucesivamente. De ahí que si en una cadena de transmisiones uno de los títulos es vicioso, entonces el defecto contagia irremediablemente a todas las transmisiones posteriores que por ello no son válidas (i.e., no permiten el nacimiento del dominio).

Como la explicación anterior pone de manifiesto, para una teoría histórica de la justicia, el problema de la justificación de la propiedad se resuelve, en último término, en el problema del modo originario de adquisición, pues por larga que sea la cadena de transmisiones los títulos derivativos (i.e., los que yo consigo de otros) no explican en definitiva

3 Nozick (1988) pp. 156 y ss.

4 Nozick (1988) p. 157. 
el nacimiento del dominio. Por eso, una teoría histórica de la justicia solo puede tener éxito en su empeño por justificar la propiedad si es que puede dilucidar el conjunto de condiciones bajo las cuales es lícita la adquisición de un bien por vez primera. El problema del modo originario de adquirir resulta, pues, decisivo para una teoría histórica. Dicho problema, por su parte, remite inevitablemente al problema del estado inicial de los bienes.

\section{LAS TEORÍAS IUSNATURALISTAS Y EL PROBLEMA DE LA COMUNIDAD ORIGINARIA}

Las teorías iusnaturalistas son teorías históricas. Como tales se ven en la necesidad de dilucidar el conjunto de condiciones bajo las cuales es posible una adquisición originaria y, con ello, en la necesidad de dilucidar el estado de los bienes antes de cualquier apropiación particular. En las teorías iusnaturalistas medievales y modernas prekantianas, este estado es concebido como una comunidad: ab initio, los bienes son comunes y esa comunidad es la llamada comunidad originaria (communio primaeva). Por consiguiente, para las teorías iusnaturalistas prekantianas, el problema de justificación de la propiedad privada consiste, fundamentalmente, en explicar la legitimidad del tránsito del estado de indivisión originario (o del "comunismo originario", como también se lo llama) al régimen de propiedad privada.

Pero "comunes" puede querer decir muchas cosas y, de hecho, el modo en que se interprete esa comunidad inicial condiciona toda la argumentación posterior en favor (o en contra) de la propiedad privada. Para ilustrar los posibles modos en que se puede entender una comunidad originaria, imaginemos -olvidando por un momento las advertencias de Nozick $^{5}$ - que un grupo de náufragos caen en una isla desierta. La pregunta ahora es ¿̇cuál es la situación particular en que se encuentran los bienes que en ella existen con respecto al grupo de náufragos? ¿Debe entenderse que son de todo solidariamente (todos son dueños del total) o distributivamente (cada uno es dueño de una parte alícuota)? ¿O que cada uno es dueño solo de alguna parte indeterminada del total? ¿O simplemente que nadie es dueño de nada y que por tanto cada uno es libre de apropiarse de lo que quiera y pueda?

Es posible pensar, por consiguiente, al menos cuatro formas de entender una comunidad originaria de bienes:

1) Originariamente los bienes son de todos en el sentido de que todos son dueños de todo in solidum. Es decir, cada individuo es dueño del total. A este caso lo denominaremos comunidad originaria positiva sensu stricto $o$ comunidad originaria positiva propiamente tal.

2) Originariamente los bienes son comunes en el sentido de que cada uno es dueño de una parte alícuota del total. A esta hipótesis la denominaremos comunidad originaria positiva divisible.

3) Originariamente cada persona es dueña de una parte indeterminada del total. Las partes de cada uno de los comuneros no son necesariamente iguales y, por el contra-

${ }^{5}$ Nozick (1988) pp. 196-197. 
rio, puede haber grandes diferencias a este respecto entre ellos. A esta comunidad la denominaremos comunidad originaria positiva simplemente conjunta.

4) Originariamente nada es de nadie, no en un sentido privativo sino tan solo negativo: los bienes son res nullius actualmente, pero potencialmente tienen dueño, pues son susceptibles de apropiación. En consecuencia, los bienes se encuentran originariamente abiertos a todos y todos tienen libertad para adquirirlos en la medida en que quieran y puedan hacerlo. Esta es la así llamada comunidad originaria negativa.

Las exigencias a que se somete la apropiación privada son en cada hipótesis diferentes. Mientras más estrictamente se conciba la comunidad originaria, más exigentes son las condiciones que deben cumplirse al momento de introducir la propiedad privada. Quien parte de una comunidad originaria positiva sensu stricto solo puede admitir la división de los bienes por medio de un acuerdo unánime y expreso de todos los comuneros, pues quien saca algo del acervo común sin la autorización de todos los demás está literalmente roban$\mathrm{do}^{6}$. De ahí que bajo esta hipótesis, los modos unilaterales de adquisición del dominio (la occupatio y el trabajo) queden a priori proscritos. Si se parte, por otro lado, de cualquier otra forma de comunidad originaria positiva, en donde las condiciones para la apropiación particular son en principio menos exigentes, podrá admitirse un acuerdo tácito como forma de división de los bienes. Asimismo, solo podrá aceptar un modo unilateral quien parte de una comunidad originaria negativa. Pero ¿en qué situación se encuentra exactamente Locke, que parece adherir a una comunidad originaria positiva pero, al mismo tiempo, abogar por un modo unilateral de adquisición del dominio? Dicho de otro modo ¡cómo puede defender Locke un modo unilateral de adquisición originaria del dominio y al mismo tiempo partir de una comunidad originaria positiva, como parece hacer?

\section{EL ATAQUE DE FILMER A LAS TEORÍAS IUSNATURALISTAS DE LA PROPIEDAD}

Locke es un defensor de la teoría de la comunidad originaria. Dicha teoría, que es el punto indiscutible de partida de las teorías iusnaturalistas medievales y modernas, no habría necesitado de la defensa que Locke le prodiga de no ser por el ataque de que en su momento fue objeto por parte de Robert Filmer. Como se sabe, Filmer defiende la tesis del origen patriarcal del poder político y de la propiedad. En conformidad con ella, Filmer entiende que la propiedad tiene su origen y justificación no en una comunidad originaria

6 Cf., por ejemplo, Proudhon: "Examinemos, sin embargo, la cuestión según la plantea Grotius: «Primitivamente, todas las cosas eran comunes e indivisas: constituían el patrimonio de todos ...» No leamos más: Grotius refiere cómo esta comunidad primitiva acabó por la ambición y la concupiscencia, cómo a la edad de oro sucedió la de hierro, etc. De modo que la propiedad tendría su origen primero en la guerra y la conquista, después en los tratados y en los contratos. Pero o estos pactos distribuyeron los bienes por partes iguales, conforme a la comunidad primitiva, única regla de distribución que los primeros hombres podían conocer, y entonces la cuestión del origen de la propiedad se presenta en estos términos: ¿cómo ha desaparecido la igualdad algún tiempo después? o esos tratados y contratos fueron impuestos por violencia y aceptados por debilidad, y en este caso son nulos, no habiéndoles podido convalidar el consentimiento tácito de la posteridad, y entonces vivimos, por consiguiente, en un estado permanente de iniquidad y de fraude". Proudhon (1985) p. 62. 
de bienes, sino en la donación que Dios hizo de los bienes a Adán en particular, y solo a él. Es decir, Adán sería el dueño de la creación y no, como tradicionalmente entendían los autores iusnaturalistas, la humanidad en su conjunto ${ }^{7}$. Filmer pretende justificar este aserto no solo en la Revelación (aunque apela fundamentalmente en ella) sino, además, en dos argumentos dialécticos: 1) la contradicción que supone afirmar por una parte que la ley natural es inmutable y por otra que la propiedad ha sido establecida por una convención. Si la comunidad de bienes es de derecho natural, entonces la convención por medio de la cual se distribuyen los bienes no es lícita, o no lo es a menos que se diga que el derecho natural muta; 2) si hubiera habido una comunidad originaria de bienes, entonces la repartición de los mismos y la introducción posterior de la propiedad privada hubiese sido imposible, pues la humanidad nunca se hubiese puesto de acuerdo en tal repartición ${ }^{8}$.

La primera de las objeciones de Filmer se refiere a la explicación que da Grocio -en sintonía con otros autores de la tradición iusnaturalista- acerca del origen de la propiedad privada y que puede resumirse así: por derecho natural los bienes son originariamente de todos ${ }^{9}$. Sin embargo, es inconveniente (o incluso imposible) mantener el estado de indivisión después del pecado original (y para demostrarlo se suele echar mano de los argumentos de Aristóteles a favor de la propiedad privada $)^{10}$. En virtud de esa constatación se entiende que la división de los bienes es lícita, más no obligatoria ${ }^{11}$, de suerte que al dividir los bienes los hombres no transgreden el derecho natural. En definitiva, toda la teoría supone que además de las leyes preceptivas y prohibitivas existe una tercera categoría de leyes, las leyes permisivas. A Filmer parece escapársele esta última categoría, pues de otro modo no habría formulado la primera de las objeciones indicadas más arriba. Como fuere, el hecho es que para los autores iusnaturalistas la humanidad obra lícitamente cuando procede a hacer división de los bienes comunes por medio de una convención (más precisamente, por derecho de gentes) ${ }^{12}$. Así, por ejemplo, afirma Tomás de Aquino:

"La comunidad de los bienes se atribuye al derecho natural, no en el sentido de que éste disponga que todas las cosas deban ser poseídas en común y nada como propio, sino en el sentido de que la distinción de posesiones no es de derecho natural, sino más bien derivada de convención humana, lo que pertenece al derecho positivo, como se ha expuesto. Por consiguiente, la propiedad de las posesiones no es contraria al derecho natural, sino que se la sobreañade por conclusión de la razón humana” (ST., II-IIae, q. 66, a.2, ad.1).

\footnotetext{
7 Filmer (1991) p. 217.

8 Filmer (1991) pp. 210 y ss.

9 Grocio, De iure belli ac pacis (abreviado en lo sucesivo como “DIBP”), II, $\$ 2.1$.

10 Cf., por ejemplo, De Soto, DII, IV, q. 3.

11 Aunque podrían encontrarse sin duda ciertos matices. Por ejemplo, De Soto afirma que solo por medio de un milagro podría subsistir la humanidad en su estado actual sin dividir los bienes (DII, IV, q. 3).

12 De Soto explica así la diferencia en DII, III, q.1.: "La diferencia, pues, no es otra más que la que nostros [sic] señalamos, a saber: que lo que se infiere como consecuencia necesaria de la absoluta naturaleza de las cosas, pertenece al derecho natural; y lo que se infiere no de la absoluta consideración de la naturaleza de las cosas, sino, como dijimos, en orden a un fin determinado, es de derecho de Gentes".
} 
Según esto, una distribución cualquiera $\mathrm{X}$ de bienes no es de derecho natural en el sentido de que ordene que el bien $Q$ pertenezca al individuo A en lugar del individuo B, sino en el sentido de que la división de las posesiones es lícita y está autorizada por el derecho natural. De hecho, la necesidad de dividir las posesiones se sigue a modo de conclusión, según Tomás de Aquino, del derecho natural ${ }^{13}$. El reparto concreto es de derecho positivo (más precisamente, hecho según el ius Gentium) y según ciertas condiciones generales, que aquí podemos pasar por alto. Aunque hay diferencias entre el modo en que Tomás de Aquino y Grocio conciben la comunidad originaria, ambos concuerdan en que la división de los bienes ha sido hecha mediante una convención de acuerdo al derecho de gentes ${ }^{14}$.

La celebración de esta convención le parece a Filmer un acontecimiento imposible:

"Ciertamente habría sido una feliz coincidencia que todos los hombres en el mundo en un instante de tiempo hubieran coincidido todos en una sola opinión para cambiar la comunidad natural de todas las cosas en dominio privado, puesto que sin tal consentimiento unánime no era posible alterar la comunidad. Pues si solo un hombre en el mundo hubiera disentido, la alteración habría sido injusta, porque ese hombre por la ley natural tenía un derecho al uso común de todas las cosas en el mundo, así que haber dado la propiedad de cualquier cosa a cualquier otro habría sido robarle de su derecho al uso común de todas las cosas” (1991, p. 234).

Obviamente, la objeción de Filmer, como señala Buckle ${ }^{15}$, descansa en una malinterpretación de la doctrina de Grocio (y podría añadirse que en una malinterpretación de las teorías iusnaturalistas de la propiedad en general). Filmer parece entender que la comunidad originaria es necesariamente una comunidad originaria positiva sensu stricto. De lo contrario, no insistiría en la necesidad de un pacto expreso y celebrado por unanimidad. No obstante, ningún autor iusnaturalista de importancia adopta ese punto de partida. Como afirma Buckle ${ }^{16}$, la teoría de la comunidad originaria (sensu stricto) es una rareza, entre otras cosas, porque el concepto mismo de propiedad supone el derecho exclusivo a usar una cosa y en una comunidad originaria positiva (sensu stricto), en cambio, no hay nadie que quede excluido del uso del bien objeto de la propiedad.

En cualquier caso, aunque Filmer no haya entendido las teorías de la propiedad que critica, Locke desestimó el contrato como modo originario de adquisición de la propiedad. En su concepto, si la propiedad hubiese sido establecida por convención, entonces sería un derecho positivo y no un derecho natural ${ }^{17}$. De ahí que al plantear el problema de la justificación de la propiedad privada en el Segundo Tratado, Locke lo haga en los siguientes términos:

\footnotetext{
13 Para la diferencia entre derivación por conclusión y por determinación, cf., AQUINO, ST., I-IIae, q. 95, a. 2.

14 Así, por ejemplo, Grocio, DIBP, II, \$II. 5.

15 BuCKLe (1991) p. 164.

16 BuCKLe (1991) p. 183.

17 LOCKE, I $\$ 88,1-13$.
} 
“[...] me esforzaré en mostrar cómo los hombres pueden llegar a tener en propiedad varias partes de lo que Dios dio en común a la humanidad, y ello sin necesidad de ningún pacto expreso de todos los comuneros” (II, \$25, 16-19).

\section{LA TEORÍA DE LA COMUNIDAD ORIGINARIA EN LOS DOS TRATADOS SOBRE EL GOBIERNO CIVIL}

Contra Filmer, Locke defiende la tesis tradicional de las teorías iusnaturalistas de la comunidad originaria de bienes. Para ello -en sintonía también con las teorías iusnaturalistas medievales y modernas- esgrime dos argumentos: uno de derecho natural y otro tomado de la Revelación. El primero viene a decir en resumidas cuentas que, dado que todos tenemos una inclinación a la autopreservación, y dado, además, que no podemos satisfacer dicha inclinación sin hacer uso de los bienes exteriores que encontramos en la naturaleza, entonces tenemos derecho a hacer uso de dichos bienes. El razonamiento puede parecer groseramente naturalista si se olvida que para Locke esta inclinación a la autopreservación ha sido implantada por Dios en el hombre ${ }^{18}$ y que por ese mismo motivo, la concibe no tanto un derecho (el hombre, dice Locke, no tiene libertad para destruirse a sí mismo ${ }^{19}$ ) como un deber: cada uno está obligado a preservarse a sí mismo y, en la medida de los posible, obligado a preservar al resto de la humanidad ${ }^{20}$. Dicha obligación arranca del hecho de que, en estricto rigor, ni nuestra vida ni la de nuestros semejantes nos pertenecen. Ellas, entiende Locke, solo pertenecen a Dios, su creador ${ }^{21}$.

Como fuere, desde el punto de vista de la ley natural, la propiedad -i.e., la posesión privada de los bienes- tiene en último término su origen y justificación en la inclinación a la autopreservación y en el derecho (Right) correlativo a dicha inclinación "de usar cualquiera de las criaturas inferiores para la subsistencia y comodidad de su vida” (I, \$92, 1-3). Como este derecho de uso derivado de la inclinación a la autopreservación es universal en un doble sentido -su titularidad corresponde a todos los individuos y tiene por objeto a todas las criaturas- su sola existencia supone a su vez la existencia de una comunidad originaria de bienes entre los hombres. Como se puede advertir, con esta argumentación -que

\footnotetext{
18 LOCKE, I, $\$ 88,13-16$.

19 LOCKE, II, \$6, 3-4.

20 LOCKE, II, \$6, 19-25.
}

21 Locke, II, \$6, 13. Con lo que, en consecuencia, la propiedad que cada uno tiene sobre sí mismo y a la que Locke se refiere en el célebre pasaje de II, $\$ 27,2-3$ no puede ser el mismo tipo de propiedad que Dios tiene sobre la Creación. Para Locke solo Dios tiene, en sentido propio y estricto, la propiedad sobre nosotros mismos. Por eso, la propiedad que nosotros tenemos sobre nosotros mismos no nos autoriza a disponer de nuestra vida ni de nuestra integridad física. Dicho de otro modo, la propiedad que tenemos sobre nosotros mismos es una tal solo metafóricamente hablando. El hecho de que para referirse al señorío (dominium) que yo tengo sobre mí mismo Locke eligiera el término propiedad (Property, proprietas) obedece, seguramente, a que Locke quiere recalcar el hecho de que el gobierno, la autoridad y, en fin, los derechos que tengo sobre mi persona -lo mío interno, como dirá Kant- son originarios y no derivan de lo suyo de otro ni de la posesión común originaria, pues Locke suele reservar el término "propiedad" (Property) para referirse a lo que en términos medievales se llama la posesión privada de los bienes (I, \$97, 14: “Adam’s Property or Private Dominium”) y que en nuestros términos corresponde a la propiedad privada. Para el uso de "property" y "suum" en Locke, cf. BuCKLE (1991) pp. 169-173; Olivecrona (1974a) p. 218 y (1974b) p. 225. 
Locke cree que nos es asequible por la sola razón- se logra un doble cometido. Por una parte, salvar el primer escollo a que tiene que hacer frente cualquier teoría de la propiedad, a saber, el problema de la posibilidad de usar los bienes en general o lo que puede denominarse también como el problema de la disponibilidad general de los bienes. Por otra, refutar la tesis del origen patriarcal de la propiedad de Filmer.

Esta refutación via rationalis de la tesis de Filmer es refrendada por la Revelación. Aquí no nos detendremos en larga argumentación ofrecida por Locke en el Primer Tratado para demostrar los errores de la interpretación de Filmer de la Escritura ${ }^{22}$. Solo importa subrayar que Locke entiende que una lectura imparcial de la Biblia nos debiera conducir al mismo resultado a que llegamos por medio de la sola razón, a saber, que existe una comunidad originaria de bienes fundada en la igualdad natural de los hombres y en el igual derecho que todos tienen de usar los bienes de la Creación para su sustento y comodidad. Así, por ejemplo, comentando el pasaje de I Gén. 28 y contrastándolo con la peregrina interpretación que hace Filmer del mismo, Locke afirma que "este texto, lejos de probar que Adán es el único propietario, es una confirmación de la comunidad originaria de todas las cosas entre los hijos de los hombres” (I, \$40, 22-24).

Por tanto, ya sea que se atienda a la ley natural, ya sea que se atienda a la Revelación, para Locke es claro que debe concluirse que los bienes son originariamente comunes. Pero ¿Cómo debe interpretarse ahora "comunes"? ¿De qué tipo de comunidad originaria debemos entender que parte Locke?

El mayor problema que suscita esta cuestión es que probablemente todas las formas de comunidad originaria que puedan pensarse tienen algún apoyo textual en alguno de los dos Tratados. Por ejemplo, en el Primer Tratado Locke afirma en varios pasajes que los hombres tienen derecho o son dueños de una porción de los bienes exteriores que Dios ha concedido a toda la humanidad. Así, por ejemplo, en el $\$ 39$ dice que

"[...] aunque los hombres están autorizados a poseer en propiedad, unos respecto de otros, ciertas porciones (Portions) de criaturas, con respecto, sin embargo, a Dios Creador del Cielo y la Tierra, único Señor y Propietario del mundo entero, la propiedad de los hombres sobre las criaturas no es sino la libertad de usarlas” (I, \$39, 47-52).

Aunque lo que Locke quiere enfatizar en este pasaje es más bien que ningún individuo particular puede ser dueño de todo el mundo con exclusión de todos los demás (i.e., el mundo en su totalidad no puede ser objeto de apropiación privada), el que hable de "porciones" (Portions) induce a pensar que la comunidad de la que parte es una comunidad originaria positiva simplemente divisible (hipótesis 2). Esa lectura es reforzada por un pasaje del $\$ 42$ donde Locke afirma que los hombres tienen una "porción particular (peculiar Portion) de las cosas de este mundo" (I, \$42, 4). El término "porciones" podría empero interpretarse también en el sentido de que la comunidad originaria positiva es simplemente conjunta (hipótesis 3).

22 Para un análisis de los distintos argumentos que Locke ofrece en el Primer Tratado, cf. WaLdron (2002). 
No obstante, en el $\$ 35$ del Segundo Tratado, y refiriéndose a la necesidad de contar con el consentimiento de los demás para apropiarse de una parcela particular de terreno en Inglaterra u otros estados, Locke aclara que "aunque sean comunes con respecto a algunos hombres, no es así con respecto a toda la humanidad; pero es la propiedad conjunta de este país [determinado] o de esta parroquia [determinada]” (II, \$35, 6-8). Es decir, respecto de ciertas parcelas de terreno existe efectivamente una comunidad (positiva) de bienes según la cual la apropiación privada de alguna parte de ellas no es posible sin el consentimiento de todos los demás comuneros. Sin embargo, dicha comunidad ha sido establecida mediante un pacto y no refleja, por consiguiente, la situación originaria de los bienes. La prohibición de apropiarse de un paño de terreno sin el consentimiento de los demás es entonces una prohibición adventicia, instaurada mediante el derecho positivo, y solo después de que alguien (unos o muchos) sacaran la mentada parcela de terreno del acervo común mediante una apropiación unilateral legítima, que no necesitó en su momento del consentimiento de todos los demás ${ }^{23}$. En el mismo sentido y más claramente aún, dice Locke en el $\$ 28$ lo siguiente:

"Vemos en los terrenos comunes, que permanecen así por convención, que es el hecho de tomar cualquier parte ellos, removiéndolo del estado en que la naturaleza lo dejó con lo que comienza la propiedad, sin la cual los bienes comunes no tienen ningún uso" (II, \$28, 16-19; énfasis añadido).

El alcance final del $\$ 28$ es particularmente revelador: si los bienes fueran ab initio comunes (en algún sentido positivo), entonces estos no tendrían ninguna utilidad. Este pasaje nos proporciona la primera pista segura en la dilucidación del tipo de comunidad originaria del que parte Locke. ¿Por qué afirma Locke que sin la propiedad privada (y, por tanto, en un sistema de propiedad común) los bienes se volverían inutilizables? ¿No es esta una afirmación muy categórica? ¿Y en cuál de todas las hipótesis de comunidad originaria positiva se está específicamente pensando Locke?

Para responder estas preguntas no debe perderse de vista el contexto del pasaje recién citado. Se trata del $\$ 28$ en que Locke argumenta a favor de la teoría del trabajo como modo originario de adquisición de la propiedad (conocida como labour-mixing theory) introducida un parágrafo antes. Dicha argumentación comienza, como se sabe, con el ejemplo de aquel que se alimenta con las bellotas o manzanas que ha recogido. Y el punto que Locke quiere dejar asentado con dicho ejemplo es que el recolector de bellotas y manzanas debe necesariamente haberse hecho dueño de las mismas precisamente al momento de recogerlas. Dicho esto, hace la siguiente reflexión:

\footnotetext{
23 La prohibición actual de apropiarse del terreno sin el consentimiento de los demás no es, no obstante, contraria al derecho natural, pues no contrario al derecho natural que posteriormente y mediante convención se determinen ciertas reglas relativas a la propiedad. En eso Locke también sigue a sus predecesores. Tully interpreta este pasaje en el sentido contrario al que Locke le quiere dar en el texto. Cf. Tully (1980) pp. 124-125.
} 
“¿Fue un robo el tomar para sí lo que pertenecía a todos en común? Si un consentimiento tal hubiera sido necesario, este hombre se hubiera muerto de hambre pesar de toda la abundancia que Dios le había dado”. (II, \$28, 13-16).

Ha de entenderse que Locke está intentando probar la idoneidad del trabajo como modo originario de adquirir el dominio mediante un razonamiento dialéctico que puede reconstruirse, grosso modo, más o menos así:

1. Necesitamos ser dueños (al menos) de los bienes consumibles con que nos alimentamos, pues de lo contrario moriríamos de hambre.

2. Es posible concebir dos modos originarios de adquisición de la propiedad: el contrato y el trabajo.

3. El contrato, empero, no puede ser el modo originario de adquirir, pues de ser así no devendríamos nunca dueños de nada.

4. (Y de no poder apropiarnos de nada, moriremos de inanición.)

$\Rightarrow$ Por tanto, el contrato no es un modo originario admisible de apropiación privada.

$\Rightarrow$ Por tanto, el trabajo ha de ser el modo originario de apropiación privada.

$\Rightarrow$ (Por tanto, ha de desecharse que la comunidad originaria haya sido una comunidad positiva sensu stricto.)

La primera proposición no es afirmada unánimemente dentro de la tradición iusnaturalista. Por el contrario, durante el siglo XIV se desató una enconada disputa entre el Papa y los franciscanos a raíz precisamente del problema de si el uso de los bienes consumibles suponía o exigía alguna forma de dominio sobre los mismos ${ }^{24}$. Locke por su parte está afirmando en su argumento implícitamente que así es. Demos, no obstante, la primera premisa del argumento de Locke por buena.

La segunda proposición deja fuera la prima occupatio, que también es un modo unilateral. Locke simplemente no considera la prima occupatio como una alternativa viable y, de hecho, ni siquiera dedica algún pasaje para explicar por qué no lo es. Como afirma Tully ${ }^{25}$, es muy probable que Locke diera por buenos los argumentos que Pufendorf ofrece en contra de la prima occupatio como modo originario de adquisición del dominio. Tales argumentos pueden resumirse así: (a) si la prima occupatio fuera un modo idóneo de adquisición de la propiedad sobre un bien, entonces los demás no podrían ni aun en estado de necesidad usar legítimamente los bienes así adquiridos por su dueño (IV, \$5, 9-18). Este argumento tiene como trasfondo un razonamiento más amplio, según el cual la propiedad solo puede tener su origen en un pacto en el que se distribuyen los bienes bajo la reserva de que, de caer alguno en estado de necesidad, ese puede usar los bienes adjudicados en el pacto a otros. Esa cláusula, entiende Pufendorf, es esencial para la instauración de la propiedad privada pues, de lo contrario, el pacto carece de toda racionalidad y no resulta oponible a

24 Cf. Tierney (1997) pp. 93-103, 170-203 y Brett (1997) 49-98. De Soto trata el problema brevemente en DII, IV, q. 1. Con mayor detenimiento se refiere también a él en la Relectio de dominio $\$ \$ 5-8$.

25 Tully (1980) p. 87. 
aquellos que se encuentren en la indigencia. Dicho de otro modo, tal como ve Pufendorf las cosas, la admisión de la occupatio como modo originario de adquisición de la propiedad conduce a la contraintuitiva conclusión de que el que se encuentra en estado de necesidad carece de todo derecho para usar las cosas de otros para conservar su vida. Esa conclusión, estima Pufendorf, debe ser evitada y el modo de hacerlo es introducir la reserva antes indicada. Dicha reserva refleja lo que podría denominarse el principio de la necesidad: bajo un estado de necesidad el pacto (o más precisamente los derechos de propiedad en él adjudicados) queda suspendido y los bienes vuelven a su estado primitivo (u originario). Por ello, la occupatio para Pufendorf es, en rigor, un modo derivativo de adquirir el dominio, en el sentido de que solo es válida una vez que se la instituye mediante un pacto, y siempre sujeta a la reserva general que sigue al principio de necesidad. Y por ello concluye al final del párrafo donde expone su primer argumento contra la prima occupatio diciendo que "para que la occupatio devenga en dominio tiene que provenir de algún pacto” (JNG, IV, \$5, 9-17). El segundo argumento (b) aduce que la prima occupatio es arbitraria: ¿por qué no iba a ser admisible en su lugar el primer avistamiento de algo ${ }^{26}$. El tercer argumento (c), finalmente, es que la prima occupatio privilegia injustamente al hombre negligente u holgazán por sobre el trabajador ${ }^{27}$. A esas tres se podría añadir aún una cuarta, que en realidad Pufendorf expone a modo de conclusión de las otras tres: (d) si los hombres tienen una igual facultad originaria (facultas primaeva) sobre los bienes, entonces no es posible entender cómo el mero acto corporal en que consiste la occupatio (i.e., la toma de posesión) podría perjudicar (praejudicare) las facultades (i.e, los derechos) de otros ${ }^{28}$. Esta última objeción toca el problema fundamental de todo intento de fundamentación de la propiedad, a saber, el de justificar la obligación que con mi apropiación impongo a todos los demás de no usar la cosa que deviene mía (efecto erga omnes de la propiedad). Pufendorf cree que la prima occupatio es en sí misma insuficiente para justificar la génesis de esa obligación y por eso se decanta por el contrato (o convención). Locke muy probablemente acepta las razones de Pufendorf en contra de la prima occupatio aunque, como se sabe, rechaza el contrato y con ella la justificación general de Pufendorf en favor de la propiedad. Todo ello no obsta, sin embargo, a que los ejemplos que Locke da de adquisición originaria por medio del trabajo sean casos paradigmáticos de prima occupatio: la caza, la pesca y la recolección ${ }^{29}$.

La tercera proposición, por su parte, es cierta si es que se está pensando en un pacto universal y expreso como modo originario de adquisición del dominio y en la comunidad originaria positiva en sentido estricto como punto de partida de la teoría de la propiedad. Ni Grocio ni Pufendorf, por ejemplo, que ofrecen una justificación convencionalista de la propiedad, apelan, empero, a pactos expresos y universales. Pufendorf, de hecho, dice explícitamente que la propiedad se introduce por un pacto "implícito e instituido" ${ }^{0}$. Ambos

\footnotetext{
26 Pufendorf, JNG, IV, \$5, 19-22.

27 Pufendorf, JNG, IV, \$5, 23-25.

28 Pufendorf, JNG, IV, $\$ 5,25-28$. Brandt, por su parte, ofrece otra explicación, no incompatible con la dada aquí, y referida a una transformación del concepto de propiedad en Locke bajo la influencia del pensamiento de Bacon. Cf. BRandt (1974) pp. 71-81.

29 LOCKE, II, \$\$26; 28.

30 Pufendorf, De iure naturae et gentium (en lo que sigue “ $J N G$ "), IV, $\$ 5,24-25$.
} 
pueden evitar el pacto expreso y universal como modo de instauración de la propiedad porque ambos parten de una comunidad originaria negativa ${ }^{31}$. Al intentar dilucidar la hipótesis de que parte Locke, llama inmediatamente la atención que este hubiere desechado el pacto como modo de justificación de la propiedad pero lo hubiere empleado profusamente para justificar otros puntos igualmente cruciales y delicados para su teoría. Por ejemplo para justificar la desigualdad a través de la introducción del dinero ${ }^{32}$ o la legitimidad de la autoridad civil en un lugar determinado ${ }^{33}$. No obstante, nuevamente es necesario hacer aquí varias aclaraciones. Locke no desecha del todo el pacto como herramienta metódica en su teoría de la propiedad: recurre al pacto tácito para justificar la distribución ampliamente desigual de las propiedades en el estado actual de la humanidad, esto es, en el estado posttrueque en el que vivimos a contar de la instauración de la economía monetaria ${ }^{34}$. Y ese es, precisamente, otro de los cometidos de su teoría de la propiedad. No obstante, y pese al importante rol que desempeña la convención en la forma final de la teoría de la propiedad de Locke ${ }^{35}$, lo cierto es que ella no desempeña papel alguno en la justificación de la adquisición originaria $\mathrm{o}$, si se prefiere, en la justificación del tránsito del estado de comunidad originaria de bienes al estado de posesión privada. La distribución actual de los bienes y, particularmente, la amplia desigualdad imperante, puede, o mejor dicho, podría eventualmente justificarse apelando a la teoría del valor y del dinero de Locke, de verificarse ciertas condiciones en la transferencia de los bienes justamente adquiridos. Dicha teoría descansa, por tanto, en la posibilidad de una apropiación original lícita, pues, al fin y al cabo, si nada es mío, no tengo nada para cambiar, vender, donar, etc. A la inversa, la teoría de la apropiación originaria de Locke sirve para explicar el tránsito del estado de comunidad originaria al estado de distribución privada de los bienes, no para justificar la distribución extremadamente desigual de los bienes. Por eso, obviamente, la teoría de la propiedad de Locke se articula combinando las dos herramientas metódicas: trabajo y convención tácita.

No obstante, para el problema que aquí nos interesa, podemos pasar por alto el problema que la convención tácita y la introducción del dinero pretenden resolver (a saber, la distribución ampliamente desigual de los bienes) para concentrarnos en lo que nos interesa: por qué Locke empleó la herramienta del contrato para resolver algunos problemas pero lo desestimó para resolver el de la propiedad en particular, y la relación que eso tiene con su concepción de la comunidad originaria. La razón para desestimar el pacto puede entresacarse de un pasaje de I \$88, 3-14 donde Locke discute si el derecho de los hijos a heredar a sus padres es o no un derecho natural. Y allí expresamente afirma que si tal de-

31 Cf. Grocio DIBP, II, \$II, 1; Pufendorf, JNG, IV, IV, \$5, 30-32.

32 LOCKe, II, $\$ \$ 45$ y ss.

33 LOCKE, II, \$119-120.

${ }^{34}$ Cf. LocKe, II, $\$ 50$. Para el papel del contrato en la teoría de la propiedad de Locke, cf. OliveCrona (1974a) p. 229: "Locke persists in rejecting the compact theory concerning the origin of property, because he negates the existence of a direct agreement as to the division of the earth. But indirectly an agreement is nevertheless taken to be the basis of the actual distribution of property, namely, the agreement to use money". Cf. también LUDWIG (2005) pp. 93-96.

35 Para el problema del papel que juega la introducción del dinero y el mercado en la teoría de Locke de la propiedad, cf. PRIDDAT (2012). 
recho existiera por convención (aunque no nos consta que haya habido un acuerdo en tal sentido), entonces no sería un derecho natural, sino únicamente un derecho positivo. Este argumento incurre en una petición de principio a menos que se entienda que la afirmación de que la propiedad es un derecho positivo exige una convención real (sea esta expresa o tácita) y no meramente hipotética, pues solo en tal caso dicha afirmación constituye una prueba en contra de la concepción convencionalista de la propiedad. El motivo por el cual Locke descarta las teorías convencionalistas de la propiedad permite, a su vez, explicar por qué Locke sí recurre al contrato al tratar otros problemas distintos de la propiedad: con razón o no, Locke parece creer que en el caso de la justificación de la desigualdad en una economía monetaria o de la autoridad civil, tiene sentido apelar al argumento del contrato pues en dichos casos los individuos han dado, aunque fuera en forma tácita, realmente su consentimiento $^{36}$. En el caso del dinero y de la autoridad del gobierno hay presumiblemente consentimiento real (aunque fuere de modo tácito), en el caso de la instauración de la propiedad, no. Así, en el caso del dinero, la conveniencia de sustituir un orden basado en el trueque por otro basado en la moneda es tan evidente que presumiblemente todo el mundo espontánea y libremente se sumaría rápidamente al nuevo sistema de intercambio (y aquí es muy tentador pensar que en su explicación del origen y justificación del dinero, Locke se encuentra ad portas de una explicación de mano invisible). El caso de la autoridad del gobierno es menos convincente pero, no obstante, es claro que Locke entendía que los individuos dan (o han dado) realmente su consentimiento al gobierno bajo el cual vivían ${ }^{37}$.

En consecuencia, y de ser todo lo anterior cierto, lo que para Locke resulta problemático no es la apelación al pacto per se (sea este expreso o tácito), sino solo la apelación a un pacto hipotético ${ }^{38}$. Dicho de otro modo, para Locke la dicotomía relevante no es entre contrato expreso y contrato tácito, sino entre contrato real y contrato hipotético. La economía monetaria y el gobierno cuentan con el consentimiento tácito pero real de los ciudadanos, pues todos usan el dinero como medio de cambio y todos celebran actos jurídicos allí donde viven. En el caso de la instauración de la propiedad, en cambio, no solo es imposible demostrar sino que además es totalmente inverosímil suponer, como observa Filmer, que alguna vez tuvo lugar un acuerdo universal con vistas a la división de los bienes. De haber sido necesario un acuerdo tal -que exige un consentimiento expreso y universal, lo que en buenas cuentas quiere decir "real"- la humanidad, como dice Locke, se hubiera muerto de hambre en medio de la abundancia ${ }^{39}$. En consecuencia, el contrato (expreso o tácito) debe ser desechado como modo originario de adquirir la propiedad por resultar impracticable: exigir un consentimiento real para el establecimiento de la propiedad lleva al absurdo de afirmar que los bienes están allí para ser usados y, al mismo tiempo, a imponer en la práctica una prohibición insuperable con respecto a su uso (o al menos del uso de los bienes con-

\footnotetext{
36 Cf. LOCKE, II, \$\$47, 50, 101-120.

37 Cf., por ejemplo, Locke, II $\$ 119$.

38 Locke no parece ni siquiera considerar la posibilidad de un pacto hipotético. Pero seguramente este le habría parecido un oxímoron. Al respecto, cf. DwORKIN (1984) p. 235.

39 LOCKE, II, $\$ 28,14-16$.
} 
sumibles), pues ahora de no contar con dicho consenso, quien saque algo del acervo común para su uso, está robando.

Esto nos lleva a la primera de las conclusiones del silogismo antes esbozado. Pero ¿se sigue la segunda conclusión de todo el razonamiento anterior?

Ciertamente la segunda conclusión - "el trabajo es el modo originario de adquisición de la propiedad"- no se sigue sin más del razonamiento esbozado antes. Por de pronto -y como adelantábamos- el trabajo es modo necesario pero no suficiente para Locke de adquisición del dominio, pues para que efectivamente dé origen a la propiedad requiere que cumpla con algunas condiciones (las así denominadas "cláusulas" o "condiciones lockeanas") que vienen a cumplir una función análoga a la que cumplía la reserva que Pufendorf exigía para el establecimiento de la propiedad: justificar el efecto erga omnes de la propiedad $^{40}$. Pero además, la idea misma de que el trabajo pueda ser título de adquisición del dominio, idea que descansa en el modelo del homo faber de Locke, requiere al menos de una justificación ulterior. Para Locke la idoneidad del trabajo como título de la adquisición parece ser más o menos axiomática. Aquí podemos darla simplemente por buena ${ }^{41}$. Ahora solo interesa subrayar que para los propósitos que persigue Locke, no es necesario demostrar que el trabajo es el único modo unilateral de adquirir posible, con exclusión de cualquier otro. Basta con que demuestre que el trabajo es un medio lícito de adquisición del dominio, con independencia de que pudiera haber algún otro (diferente de la prima occupatio, que ha quedado fuera de juego). Las así llamadas cláusulas lockeanas garantizan, precisamente, la licitud del trabajo como modo de adquirir bajo las condiciones impuestas por una comunidad originaria. Pero -y con eso volvemos a nuestro punto principal- ¡en qué tipo de comunidad originaria está pensando Locke?

Aunque la licitud del trabajo como modo originario de adquisición del dominio no se siga sin más del silogismo esbozado arriba, sí se sigue que - de ser todas las premisas ciertas- debe haber un modo unilateral lícito de adquirir el dominio. De lo contrario nos veríamos en la obligación moral de dejarnos morir de hambre. Pero obviamente el dilema morir de inanición/cometer injusticia no puede ser cierto. Nadie cuerdo estaría dispuesto a defender esa absurda alternativa. En definitiva, resulta absurdo decir, por una parte, que los bienes están a nuestra disposición para, acto seguido, sostener que dichos bienes no pueden ser utilizados, o que solo pueden serlo bajo condiciones extremadamente difíciles de cumplir, como por ejemplo un contrato universal cerrado por el consentimiento unánime de los contratantes. Un contrato tal vuelve en la práctica inutilizables los bienes. Dicho de otro modo, el contrato no es un medio factible de instauración de la propiedad. Pero nece-

\footnotetext{
40 Por tal motivo, resulta aventurado afirmar, como hace Olivecrona, que al rechazar el origen y la fundamentación convencional de la propiedad Locke también rechazó el concepto de dominium como facultas moralis Olivecrona (1974a) pp. 222-223. De una cosa no se sigue la otra. Por lo demás, de no haber concebido el dominium como una facultas moralis, Locke no habría tenido cómo concebir la propiedad en absoluto sin caer en una suerte de hobbesianismo o de realismo descarnado. Si Locke no concibiera el dominio como una facultas moralis no habría necesitado incorporar las cláusulas. La afirmación de Olivecrona solo sería cierta si es que fuera el caso que todas las facultas moralis tienen un origen únicamente convencional.

41 Respecto de este problema puede consultarse: Olivecrona (1974b); Tully (1980) pp. 116-121; WaLdron (1988) pp. 171-191; BucKLe (1991) pp. 149-161; Simmons (1992) pp. 252-277; SREenivasan (1995) pp. 59-90.
} 
sitamos la propiedad, al menos de los bienes consumibles, para poder sobrevivir. Por tanto, debe desecharse contrato como recurso para justificar la propiedad, así como todos los puntos de partida que exigen recurrir a él y resultan por tanto incompatibles con un modo unilateral de adquisición de la propiedad. Por ello, la imposibilidad de que un contrato expreso y universal sirva como medio de división de los bienes nos permite desechar retrospectivamente al menos una de las formas de comunidad originaria positiva como punto de partida de cualquier teoría admisible de la propiedad: la comunidad originaria positiva propiamente tal.

Por consiguiente, el $\$ 28$ del Segundo Tratado solo hace sentido si que Locke está pensando en una comunidad originaria positiva en un sentido estricto, pues solo bajo esa hipótesis puede afirmarse que la comunidad incurre en el absurdo de volver los bienes inutilizables.

\section{LAS CLÁUSULAS LOCKEANAS Y LA COMUNIDAD ORIGINARIA}

En el $\$ 28$ defiende la posibilidad de un medio unilateral, el trabajo, como modo originario de adquisición del dominio a partir de un argumento dialéctico: es absurdo afirmar que los bienes se encuentran a nuestra disposición y, al mismo tiempo, exigir condiciones tan difíciles de cumplir que frustren cualquier posibilidad ulterior de usarlos sin cometer un crimen. La comunidad originaria positiva sensu stricto exige recurrir a un contrato expreso y universal como modo de adquirir el dominio privado, llevándonos así a un dilema irresoluble. En consecuencia, ese tipo de comunidad debe ser desechado. Pero ¿qué sucede con los otros tipos de comunidad? Si se considera el $\$ 32$ del Segundo Tratado, se podría creer que Locke interpreta la comunidad originaria como una comunidad negativa. Un pasaje del mentado $\$ 32$ dice así:

"Tanta tierra como pueda un hombre labrar, plantar, mejorar, cultivar y usar su producto, tanta es su propiedad. Es como si, por su trabajo, cercara la tierra sacándola del terreno común. Su derecho [sobre esa tierra] no quedará invalidado por que se diga que todos los demás tienen un igual título sobre ella y que, por lo tanto, él no puede apropiársela ni cercarla sin el consentimiento de todos los otros comuneros, de todo el resto de la humanidad” (II, \$32, 4-9).

Locke resuelve el problema de la apropiación del suelo siguiendo los mismos criterios empleados para justificar la apropiación de los bienes muebles, y conforme a lo que aquí quiere decir, pareciera que Locke está defendiendo la idea de que un hombre se hace sin más dueño de la tierra que trabaja porque los demás no tienen un derecho (o más precisamente un título) sobre ella. Y todo esto querría decir que originariamente la tierra es de todos en un sentido puramente negativo. No obstante, la posibilidad de que Locke parta de una comunidad originaria negativa debe ser rechazada. La razón de ello es que, como advertíamos, Locke no entiende que el trabajo invertido o ejercido en una cosa que carece de dueño dé sin más la propiedad de dicha cosa. Por el contrario, Locke cree que una apropiación unilateral en estado de natural solo resulta vinculante para los otros cuando es 
hecha bajo ciertas condiciones que han llegado a ser conocidas como las cláusulas lockeanas. La primera, la cláusula de no desaprovechamiento, fija un límite a las apropiaciones unilaterales en estado de naturaleza y en general a la propiedad antes de la introducción del dinero. Conforme a ella, cada individuo puede apropiarse de tanto como sea capaz de usar y disfrutar antes de que estropee. Lo que cada uno se apropia por sobre tal cantidad, pertenece a otros:

"Dios nos no ha dado todas las cosas en abundancia [...] Pero ¿̨hasta dónde nos las ha dado? Hasta donde podamos disfrutarlas. En tanto pueda uno hacer uso de algo para ventaja de su vida antes de que se estropee, puede fijar en ello su propiedad por medio del trabajo. Lo que excede esta medida es más que su parte y pertenece a otros. Nada fue hecho por Dios para el hombre para que el hombre lo estropeara o destruyera” (II, \$31, 7-11).

Resulta decisivo que en este pasaje en el que es enunciada la cláusula Locke hable de la "parte" (share) que le corresponde a cada uno. Solo puede haber "partes" si es que los bienes se encuentran originalmente bajo alguna forma de comunidad positiva (diferente de la comunidad positiva en sentido estricto), y más precisamente de una comunidad positiva divisible, pues solo en ella al dejar perecer bienes en mi poder no solo daño las expectativas de otros, sino sus derechos. Locke no dice simplemente que el que deja perecer inútilmente bienes en su poder perjudica las expectativas de otro o que, en fin, incurre en una dilapidación lamentable e incluso irracional de recursos. Dice explícitamente que aquello que nos apropiamos por sobre nuestra capacidad de aprovechamiento, pertenece a otros. Solo bajo una comunidad positiva divisible una afirmación tan fuerte tiene asidero.

No obstante, la segunda cláusula, la cláusula de suficiencia ${ }^{42}$, parece apuntar en una dirección diferente. Locke introduce esta cláusula al momento de tratar específicamente la apropiación de la tierra. La apropiación de la tierra tiene lugar también por medio del trabajo $(\$ 32)$ pero, puesto que de todos los bienes, este es el único cuyo acervo es fijo y no podemos multiplicar por medio del trabajo, Locke se cuida de hacer la siguiente observación:

"Ni fue esta apropiación de una parcela de tierra por medio de su cultivo causa de perjuicio para ningún otro hombre, pues todavía quedaban tierras suficientes e igualmente buenas, y más de la que todavía otros podrían haber usado. Así que, en efecto, no hubo dejado nunca menos para otros a causa de su apropiación (inclosure), pues aquel que deja tanto como el otro puede usar en realidad es como que no hubiera tomado nada en absoluto" (II, \$33, 1-7).

Un poco más abajo, y refiriéndose a la donación de Dios en favor de los hombres, de la apropiación y el cultivo de la tierra, Locke reitera la cláusula:

${ }^{42}$ Contra la primera de las cláusulas, cf. WaLdron (1979). En contra de la tesis de Waldron, SREENIVASAN (1995) pp. 37-50. 
"Aquel al que le ha quedado tanto para su propia mejora como otros han tomado ya, no necesita quejarse y no debe entrometerse con lo que ya ha sido mejorado por el trabajo de otro. Si lo hiciera, es evidente que estaría deseando el beneficio de los esfuerzos de otro, a lo que no tiene derecho, y no la tierra que Dios le ha dado en común con los otros para que la trabaje y de la que queda tanta como la que ya ha sido poseída y más de la que él puede aprovechar o abarcar con su industria” (II, \$34, 7-14).

Obviamente, es imposible cumplir con la cláusula de suficiencia si es que se la entiende de modo literal. Por de pronto, exigiría conocer el estado total del mundo al momento de sacar algo del acervo común. Además, en el caso de los bienes no renovables -o, mejor dicho, cuya cantidad no podemos multiplicar por medio del trabajo, como la tierra- no habría forma de cumplir la cláusula, pues cualquier apropiación efectivamente estaría reduciendo el stock de bienes disponibles en el mundo ${ }^{43}$. Por tanto, la cláusula debe ser interpretada en un sentido amplio: una apropiación es lícita si y solo si con ella no se perjudica a los otros ${ }^{44}$. Eso supone que pueda cumplirse la condición por equivalencia: yo devuelvo aquello que quito del acervo común. Esta posibilidad de cumplir la cláusula por medio de alguna prestación equivalente no solo permite pensar en un argumento adicional en favor del trabajo por sobre la prima occupatio, sino que además permite resolver el problema de la adquisición originaria no convencional de un bien en estado de naturaleza: si mi apropiación tiene lugar por medio del trabajo, mis apropiaciones tienden a crear o multiplicar el acervo de bienes disponibles y, con ello, estoy devolviendo a la comunidad aquello que le quité ${ }^{45}$. Esta multiplicación me exime de la necesidad de contar con el consentimiento de los demás para realizar apropiaciones, pues en virtud de dicha multiplicación estoy manteniendo o incluso aumentando el acervo total de bienes disponibles ${ }^{46}$. Esta interpretación de la cláusula de suficiencia, empero, está expuesta a una objeción obvia: al apropiarme de algo por medio del trabajo yo no dejo la comunidad de bienes intacta, pues por mucho que multiplique los bienes, aquellos bienes que produzco son míos, no comunes $^{47}$. Este reproche solo resulta fatal si se interpreta la comunidad originaria de bie-

43 Así la interpreta, por ejemplo, Rothbard: "La cláusula de Locke puede conducir a la proscripción de toda propiedad privada de la tierra, puesto que uno siempre puede decir que la disminución de los territorios disponibles deja a todos los que podrían haberse apropiado de dicho territorio en peor situación”. RotHBARD (1998) p. 244.

${ }^{44}$ Nozick (1988) pp. 179-183.

45 Es célebre el pasaje donde Locke afirma que un jornalero en Inglaterra vive mejor que un rey en América (II, $\$ 41,8-10$ ). Esa diferencia, como se sabe, la atribuye Locke al trabajo y, más específicamente, al aumento de valor de las cosas como consecuencia del trabajo invertida en ellas. Macpherson, por su parte, sostiene, seguramente con razón, que la justificación de Locke del dinero supone la caducidad de la cláusula de suficiencia o, al menos, la posibilidad de cumplirla por algún medio equivalente. Cf. MACPHERson (2005) pp. 209-212. De ser esto así, para el éxito de su argumentación, Locke necesita que una economía monetaria sea lo suficientemente eficiente en la producción de los bienes como para aumentar el nivel general de vida y, de este modo, poder cumplir la cláusula por equivalencia. La interpretación de Macpherson, por otro lado, como se sabe es sumamente crítica con esta solución de Locke al problema que supone por la cláusula de suficiencia.

${ }^{46}$ LOCKE parece estar apelando a un argumento de este tipo en II, $\$ 37$.

47 "MacPherson has mistaken Locke's argument in the passage [i.e., aquel en que Locke compara la productividad de un acre de tierra cultivado con la de otro sin cultivar]. When a man encloses and cultivates ten acres of hitherto common land, the rest of man-kind is benefited, according to Locke, by the greatly reduced pressure on the remaining 
nes como una comunidad positiva divisible. Solo en una comunidad tal, en que cada uno es dueño de una cuota indeterminada del total tal reproche tiene sentido. Bajo una comunidad positiva simplemente conjunta (y con mayor razón en una comunidad originaria negativa) la objeción carece de sentido y podría, además, ser respondida -en una vena muy libertaria, es cierto- diciendo que mantener la comunidad indemne no significa dar directamente a otros parte de los bienes que son producto de mi trabajo, sino tan solo ofertarlos en un mercado libre, de suerte que los otros puedan adquirirlos a través de su trabajo por las vías jurídicas ordinarias (compraventa, permuta, etc. ${ }^{48}$. Eso supone, obviamente, que los otros trabajen para conseguir las cosas que oferto. No obstante, para Locke de ahí no puede elevarse una objeción seria, pues esos otros igualmente debieran haber trabajado los bienes comunes para poder sacarlos de la comunidad originaria. Salvo, como veremos, el caso de necesidad, no hay para Locke modo de adquirir algo si no es por medio del trabajo.

Por tal motivo, llegado este punto, hay solo dos alternativas: negar que la cláusula de suficiencia sea en realidad unas de las cláusulas a que Locke sujeta la validez de las apropiaciones originales o negar que la comunidad originaria de bienes pueda ser una comunidad positiva divisible.

Aun cuando la interpretación cláusulas nos lleve en direcciones divergentes a la hora de intentar reconstruir retrospectivamente el tipo de comunidad del que parte Locke, sí es posible, no obstante, sacar en limpio ciertas conclusiones, pues por muy controvertida que resulte el sentido y alcance de las cláusulas lockeanas, seguramente es posible afirmar que a ambas subyace la misma lógica: una apropiación unilateral bajo una comunidad originaria positiva (divisible o simplemente conjunta) es lícita si al realizarla, el adquirente se cuida de dejar indemne los derechos de terceros. La lógica de las cláusulas, entonces, es que las apropiaciones unilaterales solo resultan vinculantes si es que al realizarlas se dejan a salvo, incólumes, los derechos de terceros, pues solo entonces puede prescindirse legítimamente del consentimiento de dichos terceros para sacar algo del acervo común. No debe, pues, perderse de vista que la teoría de la propiedad de Locke es una teoría que pretende explicar el surgimiento de la propiedad privada sin recurrir al consenso, es decir, explicar la propiedad por medios no contractuales. Ahora bien, de partir de una comunidad originaria negativa, Locke no necesitaría incluir en su teoría de la propiedad las así llamadas cláusulas (o estipulaciones) lockeanas, pues entonces no se suscitaría el problema del consenso. Por consiguiente, la inclusión de las cláusulas es una prueba de que Locke parte de alguna forma de comunidad originaria positiva. De lo contrario las estipulaciones no tendrían razón de ser. Bajo una comunidad originaria negativa las apropiaciones unilaterales son sin más lícitas: si yo me apropio de algo que es res nullius no lesiono con ello los derechos de nadie. Por ello, de haber partido Locke de una comunidad originaria negativa, su teoría de la apropiación

common land. To produce the same goods that he is produc-ting by cultivation, a hunter and gatherer would need to roam over a hundred acres of common land. So by withdrawing from the common into his ten acre patch, the encloser leaves the remaining ninety acres that much freer for everybody else. It is not, however, Locke's argument that mankind benefits from the product of the ten cultivated acres: the only person who benefits from that is the cultivator." WALDRON (1979) p. 323.

48 Una interpretación de este tipo ofrece Gauthier de la(s) cláusula(s). Cf. Gauthier (2000) pp. 268-307; pp. 352-399. 
originaria podría haber seguido una lógica muy semejante a la de, por ejemplo, Rothbard: el trabajo basta por sí solo para adquirir el dominio de las cosas que son res nullius ${ }^{49}$.

De ahí que, aun cuando la consideración de las cláusulas no sea por sí misma suficiente para determinar de qué tipo de comunidad positiva parte Locke, sí es suficiente para determinar de qué tipo de comunidad originaria no parte: de una comunidad originaria negativa. De ahí que Waldron lleve razón cuando afirma que Locke no cree que el comunismo original deba ser pensado como un estado vacío de derechos (1988, p. 155): en el estado de naturaleza lockeano todos los individuos tienen ab initio algún tipo de derecho, más o menos determinado, sobre los bienes externos que se encuentran en la naturaleza. Como es fácil imaginar, esa suposición es la más criticada y controvertida de las teorías de la comunidad originaria ${ }^{50}$. Para dilucidar qué tipo de derecho es ese y cuál es su extensión en el caso particular de Locke no es suficiente, como ha quedado claro, con el examen del tratamiento que hace de la apropiación original. Es preciso atender a la estructura general de su teoría de la propiedad y, más precisamente, a un derecho particular que contribuye de modo decisivo a moldear esa estructura: el derecho al excedente que tiene aquel que está en estado de necesidad y que Locke trata en el Primer Tratado.

\section{LA NECESIDAD, LA CARIDAD Y EL DERECHO NATURAL DE USO}

Un importante pero frecuentemente olvidado pasaje del Primer Tratado puede contribuir decisivamente a la dilucidación del tipo de comunidad originaria de la que parte Locke. Dicho pasaje dice así:

"Pero nosotros sabemos que Dios no ha dejado ningún hombre a la clemencia de otro, de modo que lo pueda dejar morir de hambre si le place. Dios, el Señor y Padre de todos, no ha dado a ninguno de sus hijos tal propiedad sobre su porción particular de las cosas de este mundo, sino que ha dado a su hermano necesitado un derecho sobre el excedente (Right to Surplasage) de sus bienes, de modo que no se le pueden negar justamente cuando sus necesidades apremiantes lo reclamen [...] Porque siempre será pecado si un hombre de posición deja perecer en la necesidad a su hermano por no darle algo de lo mucho que tiene. Así como la justicia otorga a cada hombre el derecho sobre el producto de su honesta industria y a las legítimas adquisiciones que sus antecesores le legaron, así la caridad da a todos los hombres un derecho sobre lo que la abundancia de otro, para mantenerlos alejados de la necesidad extrema, en tanto carezcan de medios para subsistir de otra manera” (I, $\$ 42,1-15$ ).

En este pasaje hay ciertas formulaciones que suscitan algunas dudas ${ }^{51}$. El punto central radica en que aquellos que se encuentran sin culpa en estado de necesidad tienen un derecho aquello que a otros les sobra. No obstante, Locke afirma que el título por el cual

\footnotetext{
49 Rothbard (1998) pp. 29-34.

50 Cf., por ejemplo, Feser (2005); Brrd y HruschKa (2010) pp. 122-142.

51 Para una interpretación del pasaje del Primer Tratado citado recién, cf. Simmons (1992) pp. 327-335.
} 
los que se encuentran en estado de necesidad disfrutan ese derecho es la caridad, no la justicia. En relación al problema que aquí nos ocupa, es tentador suponer que Locke atribuyó la fuente de tal derecho al excedente a la primera y no a la segunda porque la segunda exige que la comunidad originaria de bienes sea positiva en alguno de los primeros dos sentidos indicados más arriba, y que Locke no pretendía adoptar alguna de esas hipótesis como punto de partida de su propia teoría de la propiedad a causa de los problemas que estas hipótesis plantean y que ya hemos revisado.

Pero por otra parte tampoco es necesario hacer conjeturas acerca de la intención de Locke. Pese a la ambigüedad introducida con la distinción entre el título derivado de la justicia y el título derivado de la caridad, el pasaje recién citado bien puede leerse simplemente como la continuación de la doctrina tradicional del derecho de necesidad ${ }^{52}$. En la escolástica, el derecho de necesidad es sistematizado a partir, fundamentalmente, de la famosa fórmula de Aristóteles que dice que "es mejor que la propiedad sea privada, pero su utilización común" ${ }^{3}$. Por ejemplo, Tomás de Aquino -a quien siguen de cerca los autores de la Escuela de Salamanca- integra la fórmula de Aristóteles con las teorías de la comunidad originaria, ya muy difundidas en el derecho canónico de su época ${ }^{54}$. En el principio, sostiene Tomás, todos los bienes son comunes. Pero como el estado de indivisión produce múltiples inconvenientes, los hombres proceden a hacer división de las cosas comunes ${ }^{55}$. Esa división, como se ha indicado ya, es de derecho positivo y no es en rigor obligatoria desde el punto de vista del derecho natural. Es simplemente lícita. Con eso, no obstante, alcanza para que la posesión privada de los bienes quede amparada por el derecho natural. A condición, claro está, de que no contravenga la disposición fundamental del derecho natural según la cual, todos los hombres tienen el dominio natural de los bienes en lo que respecta al uso de los mismos ${ }^{56}$. Esta tesis, según la cual los hombres tienen el dominio natural de los bienes en lo que respecta a su uso supone varias $\operatorname{cosas}^{57}$. Pero desde un punto de vista estrictamente jurídico -que es el que aquí nos interesa- significa primero, que la humanidad no es dueña, en rigor, de la creación, sino tan solo su usufructuaria o propietaria fiduciaria; y en segundo lugar, que todos los hombres tienen un igual derecho a hacer uso de las cosas para asegurar su propia subsistencia. Este "dominio natural" -que llamaremos derecho natural de uso- conduce directamente a la idea de una comunidad originaria de bienes. Dicha comunidad impone tan solo un límite a la división que posteriormente se haga en virtud del ius Gentium: que no quede nadie en estado de necesidad. Dicho de otro modo, los hombres tienen un amplio espacio para acordar diferentes modos de división de los bienes,

52 "[T] he right of charity can be regarded as Locke's version of the right of necessity acknowledged by Grotius and Pufendorf" (BuCKLE 1991, p. 160).

53 Aristóteles, Política, II, 5, 1262a 38-39.

54 Cf. Tierney (1997) pp. 135 y ss.

55 Aquino, ST., II-IIae, q. 66.

56 Aquino, ST., II-IIae, q. 66, a.1.

57 Por de pronto, que el hombre no tiene un dominio pleno sobre las cosas porque no puede disponer de la naturaleza de las mismas. El orden natural está ahí, ya dado para el hombre y no lo puede modificar, en el sentido de que no puede modificar a su antojo las leyes naturales que gobiernan el mundo. Cf., por ejemplo, la explicación que sobre este mismo asunto da Domingo de Soto en su Relectio de dominio \$18, 1-7. 
según la conveniencia que les reporte un modo u otro en un momento y lugar dado, pero bajo ningún respecto puede ocurrir que la división se haga de tal modo que, después de celebrada la convención, algunos queden sin nada. Respecto de estos últimos, la convención es inoponible, y por eso afirma Tomás de Aquino que:

"Lo que es de derecho humano no puede derogar el derecho natural o el derecho divino. Ahora bien, según el orden natural instituido por la divina Providencia, las cosas inferiores están ordenadas a la satisfacción de las necesidades de los hombres. Por consiguiente, su división y apropiación, que procede del derecho humano, no ha de impedir que con esas mismas cosas se atienda a la necesidad del hombre. Por esta razón los bienes superfluos que algunas personas poseen son debidos, por derecho natural, al sostenimiento de los pobres [...] [s]i la necesidad es tan evidente y urgente que resulte manifiesta la precisión de socorrer la inminente necesidad con aquello que se tenga, como cuando amenaza peligro a la persona y no puede ser socorrida de otro modo, entonces puede cualquier lícitamente satisfacer su necesidad con las cosas ajenas, substrayéndolas, ya manifiesta, ya ocultamente. Y esto no tiene propiamente razón de hurto ni de rapiña" (ST., II-IIae, q. 66, a.7 $)^{58}$.

Dicho de otro modo, los hombres tienen un derecho originario inalienable para hacer uso de aquellas cosas que les son necesarias para su subsistencia. Este derecho originario e inalienable que Tomás llama "de uso" se sobrepone, en consecuencia, a cualquier arreglo ulterior a que arriben los hombres con respecto a la gestión, disposición y distribución de los bienes. Por el modo en que concibe y trata dicho derecho de uso, es claro que Tomás de Aquino parte de lo que aquí hemos llamado una comunidad originaria positiva simplemente conjunta ${ }^{59}$. De partir de alguna otra forma de comunidad positiva, los criterios para proceder a la distribución de los bienes tendrían que ser menos laxos y los derechos de aquellos que se encuentran en estado de necesidad serían más robustos y exigentes: podrían consistir no solo en un derecho a tomar lo estrictamente necesario para su conservación de aquello que le sobra a otro sino que estarían autorizados a exigir algo más. Pero además -y esto es decisivo- de partir de alguna comunidad positiva diferente de la simplemente conjunta, el deber de socorro que tienen aquellos que poseen bienes en abundancia para con aquellos que se encuentran en estado de necesidad sería un deber de justicia y no única-

58 Cf. también Aquino, ST., II-IIae, q. 32, a. 5, ad. 2: "Los bienes temporales que divinamente se confieren al hombre, son ciertamente de su propiedad; pero su uso no solamente debe ser suyo, sino también de aquellos que pueden sustentarse con lo superfluo de ellos".

59 "El Aquinate ha podido, pues, armonizar los dos puntos de vista en apariencia antitéticos: que la comunidad de posesiones es de derecho natural, en el sentido negativo de que su dictamen e intención primaria sobre los bienes de la tierra no impone la división de las propiedades, sino da a todos los hombres un derecho común e igual a poseer y usar de ellos para sus necesidades". Introducción a la cuestión 66, p. 484 en la edición de la Suma consultada. Esta afirmación es cierta solo si se entiende que la comunidad originaria positiva es aquella en que todos son solidariamente dueños de todo, es decir, que la comunidad originaria positiva es únicamente la que aquí hemos denominado comunidad originaria positiva en sentido estricto o propiamente tal. Si se toma comunidad originaria positiva en ese sentido, entonces es cierto que Tomás de Aquino no parte de una comunidad originaria positiva. 
mente de caridad ${ }^{60}$. Pero el título que para Tomás de Aquino tiene el necesitado en contra del rico es la caridad, no la justicia ${ }^{61}$. Si la comunidad originaria positiva fuera divisible, entonces el título del necesitado sería un título jurídico en sentido estricto (i.e., exigible coactivamente). Si, por otra parte, Tomás de Aquino hubiera partido de una comunidad originaria negativa -en la que no existe un derecho universal de uso sino tan solo una libertad para apropiarse de bienes- entonces no habría tenido cómo afirmar que aquellos que se encuentran bajo un estado de necesidad tienen algún título que invocar contra los ricos para usar aquellas cosas que les resultan indispensables para aliviar su necesidad ${ }^{62}$.

Este razonamiento de Tomás de Aquino -que aquí presentamos a muy grandes rasgos, obviamente- es reproducido por los autores escolásticos posteriores ${ }^{63}$ y es muy probable que en el $\$ 42$ del Primer Tratado citado más arriba, Locke -que leía ciertamente a los autores de la Escuela de Salamanca ${ }^{64}$ - no esté, por su parte, más que haciendo otro tanto, a saber, reproducir la que era la doctrina común en su época acerca del origen de la propiedad privada introduciendo, únicamente, una "pequeña" variación en la explicación del tránsito de la comunidad originaria a la posesión privada de los bienes con el propósito de eludir las objeciones de Filmer: reemplazar la convención realizada al alero del ius Gentium por el trabajo (sujeto al cumplimento de ciertas condiciones) como modo unilateral de adquisición del dominio. Conservando el punto de partida tradicional de la comunidad originaria positiva (simplemente conjunta), Locke puede además evitar las conclusiones contra intuitivas que prima facie se siguen de la adopción de un modo unilateral de adquisición del dominio: que aquel que se encuentra en estado de necesidad carece de todo derecho contra los poseedores para garantizar su subsistencia, aun cuando esos poseedores naden en la abundancia. Pero conservando dicho punto de partida, Locke está en condiciones de afirmar algo que al menos prima facie es bastante semejante a lo que afirma Tomás de Aquino: la introducción de la propiedad privada, y los arreglos ulteriores que se cierren en orden a hacerla operativa ${ }^{65}$, no obstan ni suprimen ni pueden suponer una abrogación del derecho natural originario al uso de aquellas cosas que todos necesitamos para sobrevivir. Por consiguiente, quien se encuentra en estado de necesidad tiene un derecho no exigible coactivamente contra aquel que tiene excedentes por dichos excedentes para asegurar su propia

${ }^{60}$ Cf., Aquino, ST., II-IIae, q. 32, a. 5.

${ }^{61}$ De Soto por su parte lo afirma tajantemente: "No creas que la primera conclusión [i.e., aquella que establece un derecho al excedente en favor del necesitado] implica una obligación de justicia, sino solo de misericordia, como hemos advertido en el libro 4 en la división de las cosas. Porque después que estas han sido divididas, cada uno es dueño de las suyas; sin embargo el común derecho natural subsiste hasta el punto de que quien tenga de sobra, debe de mostrarse generoso con los pobres. Por este motivo de aquí brota la verdad de la conclusión segunda; o sea, que nadie, aunque esté gravemente necesitado, puede robar a uno que esté rico. Y no vale decir que el rico en tal caso, es decir, de extrema necesidad, está obligado a auxiliar al pobre, según lo que dice San Juan en su canónica: Quien viere a su hermano padecer necesidad y le cerrara las puertas de su corazón, ¿cómo puede tener caridad? Y por tanto puede por sí mismo robarle sus bienes; porque tal obligación no es de justicia, sino de caridad, a la cual nadie puede ser obligado en contra de su voluntad”. De Soto, DII, V, q. 3, a.4.

62 Cf., por ejemplo, Aquino, ST., II-IIae, q. 66, a. 7, ad.1.

63 Cf., por ejemplo, De Soto, DII, IV, q. III.

${ }^{64}$ Tully (1980) pp. 64-68.

65 LOCKE, II $\$ \$ 38 ; 45 ; 50$. 
subsistencia. Esta concordancia con la tradición escolástica no significa, por supuesto, que los "pequeños" cambios que Locke introduce en la explicación y justificación de la propiedad no terminen, a la larga, configurando una teoría de la propiedad (y una teoría política) nueva y original al interior de la tradición iusnaturalista. Aquí baste únicamente subrayar que el derecho que Locke defiende en el $\$ 41$ del Primer Tratado -tal como sucedía en el caso de Tomás de Aquino, y por las mismas razones-, solo es compatible con lo que aquí hemos denominado una comunidad originaria positiva simplemente conjunta.

\section{CONCLUSIONES}

Locke no es todo lo explícito que pudiera quererse con respecto a la cuestión del estado en que originariamente se encuentran los bienes. No obstante, su concepción de la comunidad originaria de bienes puede establecerse con cierta seguridad si, además de indagar en los antecedentes escolásticos de Locke, se realiza una suerte de reconstrucción retrospectiva con vistas a la determinación del punto de partida que mejor casa con la argumentación general que ofrece a favor de la propiedad. En primer lugar, dicha argumentación apela, fundamentalmente, a un razonamiento dialéctico que intenta poner de manifiesto el absurdo al que conduce el hecho de exigir un contrato expreso y universal para salir de la comunidad originaria. En la práctica un contrato de esta índole haría de los bienes comunes res nullius y, más exactamente, como diría Kant, res nullius en $s^{66}$. Así, por una parte, aunque quien exige un contrato tal se ve en la necesidad de admitir que los bienes están allí para ser usados, por otra impide dicho uso con las restricciones que impone a la apropiación privada. Si los bienes hubieran sido ab initio poseídos in solidum, nadie podría hacer uso de nada sin cometer una injusticia, con lo que todos deberían resignarse a morir de hambre antes de sacar nada del acervo común. Así, si el contrato expreso y universal debe desecharse como modo originario de adquirir, debe desecharse entonces también el punto de partida que necesariamente lo exige: la comunidad originaria positiva en sentido estricto.

La comunidad originaria positiva en sentido estricto es del todo incompatible con el propósito primordial de Locke de ofrecer una fundamentación no contractual de la primera apropiación. No obstante, de aquí no se sigue que Locke se represente la situación inicial de los bienes como sometida a las reglas de una comunidad originaria negativa. El hecho, por el contrario, de que Locke sujete la validez de las apropiaciones unilaterales en estado de naturaleza al cumplimiento de ciertas condiciones permite de entrada desechar la hipótesis de una comunidad originaria negativa: en una comunidad negativa, las apropiaciones unilaterales son sin más lícitas, pues por definición yo no daño a nadie al apropiarme de una res nullius.

La mayor dificultad, por tanto, estriba en discriminar entre la comunidad positiva divisible y la comunidad positiva simplemente conjunta. Y dicha dificultad no puede ser resuelta orientándose únicamente a partir del sentido y alcance de las cláusulas lockeanas, pues estas no permiten decidir de modo concluyente entre alguna de las dos comunidades positivas restantes. Por ello resulta esencial tomar en consideración el derecho al excedente

66 KANT, AA VI, 246-247. 
que tiene aquel que está en estado de necesidad. Ese derecho en una teoría que expresamente parte de una comunidad originaria de bienes, es consecuencia del derecho originario y universal de uso para asegurar la propia subsistencia, derecho al que Locke se refiere expresamente en I, $\$ \$ 88$ y 92 . Un “derecho” tal, cuyo título es la caridad y, en consecuencia, no es exigible coactivamente, es empero demasiado exiguo como para poder emanar de cualquier comunidad originaria positiva que no sea la simplemente conjunta. En el caso de la una comunidad originaria positiva divisible, la presión por una distribución igualitaria es mucho mayor. Después de todo, en este tipo de comunidad cada individuo es dueño de una parte alícuota del total, de suerte que, en rigor, en concordancia con ella los necesitados podrían exigir una redistribución de bienes y no solo lo necesario para poder subsistir, y todo ello amparados por un título dotado de fuerza coactiva.

\section{BIBLIOGRAFÍA}

Aquino, Tomás de (1956): Suma Teológica, vol. VIII (trad. Teófilo Urdanoz, Madrid, Biblioteca de Autores Cristianos).

Aristóteles (2005): Política (Trad. Julián Marías y María Araujo, Madrid, Centro de Estudios Políticos y Constitucionales).

Brett, Annabel S. (1997): Liberty, Right and Nature. Individual Rights in Later Scholastic Thought (New York, Cambridge University Press).

BRANDT, Reinhard (1974): Eigentusmtheorien von Grotius bis Kant (Stuttgart-Bad Cannstatt, Frommann-Holzboog).

Buckle, Stephen (1991): Natural Law and the Theory of Property: Grotius to Hume (Oxford, Oxford University Press).

Byrd, B. Sharon y Hruschka, Joachim (2010): Kant's Doctrine of Right. A Commentary (New York, Cambridge University Press).

De Soto, Domingo (1968): De iustitia et iure libri decem - De la justicia y el derecho en diez libros, tomo II (Trad. Marcelino GonzÁlez Ordóñez, Madrid, Instituto de Estudios Políticos).

De Soto, Domingo (1995): Relecciones y opúsculos, vol. I (Trad. Jaime Brufau Prats, Salamanca, editorial San Esteban).

Dworkin, Ronald (1984): Los derechos en serio (Trad. Marta Guastavino, Barcelona, Editorial Ariel).

FESER, Edward (2005): “There is no such thing as an unjust initial acquisition" en: Franken Paul, Elle Miller Jr., Fred. D. Paul, Jeffrey (edits.), Natural Rights Liberalism from Locke to Nozick (Cambridge, Cambridge University Press), pp. 56-80.

Filmer, Robert (1991): Patriarcha and Other Writings (Edit. Peter Laslett, New York, Cambridge University Press).

Gauthtien, David (2000): La moral por acuerdo (Trad. Alcira Bixio, Barcelona, editorial Gedisa).

Grocio, Hugo (1919): De iure belli ac pacis libri tres. In quibus ius naturae et gentium, item iuris publici praecipua explicantur. (Ed. P. C. MolHuysen, Leiden, Sijthoff). 
Kant, Inmanuel ( $\left.{ }^{3} 2002\right)$ : Metafisica de las Costumbres (Trad. Adela Cortina Orts y Jesús Conill Sancho, Madrid, editorial Tecnos).

LudwiG, Bernd (2005): "John Lockes Eigentums Theorie" en: EcKL, Andreas - LudwiG, Bernd (edits.) Was ist Eigentum? Philosphische Positionen von Platon bis Habermas (München, Beck), pp. 88-102.

Macpherson, Crawford Brough (2005): La teoría politica del individualismo posesivo: De Hobbes a Locke (Trad. Juan-Ramón Capella, Madrid, Editorial Trotta).

Nozick, Robert (1988): Anarquí, Estado y utopía (Trad. Rolando TamaYo, México, Fondo de Cultura Economómica).

Locke, John ( $\left.{ }^{3} 1988\right)$ : Two Treatises of Government (Edit. Peter Laslett, Cambridge, Cambridge University Press).

Locke, John (21997): Dos ensayos sobre el Gobierno Civil (Trad. Francisco Giménez Gracia, Madrid, Espasa Calpe).

LOCKE, John (2002): Segundo tratado sobre el gobierno civil un ensayo acerca del verdadero origen alcance y fin del gobierno civil (Trad. Carlos Mellizo, Madrid, Alianza Editorial), 238 pp.

Olivecrona, Karl (1974a): "Appropriation in the State of Nature: Locke on the origin of Property", Journal of the History of Ideas, vol. 35, no 2: pp. 211-230.

Olivecrona, Karl (1974b) "Locke's Theory of Appropriation", The Philosophical Quarterly, vol. 24, no 96: pp. 220-234.

Pufendorf, Samuel (1998): Gesammelte Werke, tomo 4, De iure naturae et gentium, liber quartus (Eds: Wilhelm Schmidt-Biggemann Frank Böhling, Berlin, Akademie Verlag).

Priddat, Birger P. (2012): "Eigentum, Arbeit, Geld: Zur Logik einer Naturrechtsökonomie bei John Locke”, en: Rehm, Michaela - Ludwig, Bernd (edits.), Zwei Abhandlungen über die Regierung (Berlin, Akademie Verlag), pp. 79-93.

Proudhon, Pierre Joseph (1985): ¿Qué es propiedad? (Trad. Rafael García Ormaechea, Barcelona Ediciones Orbis).

Rothbard, Murray N. (1998): The Ethics of Liberty (New York, New York University Press).

Simmons, A. John (1994): The Lockean Theory of Rights (New Jersey, Princeton University Press).

Sreenivasan, Gopal (1995): The Limits of Lockean Rights in Property (New York-Oxford, Oxford University Press).

Tierney, Brian (1997): The Idea of Natural Rights (Michigan-Cambridge, William B. Eerdmans Publishing Company).

Tully, James, A. (1980): Discourse on Property. John Locke and his Adversaries (Cambridge, Cambridge University Press).

Waldron, Jeremy (1979): "Enough and as Good Left for Others", The Philosophical Quarterly, Vol. 29, No. 117, pp. 319-328.

Waldron, Jeremy (1990): The Right to Private Property (Oxford, Oxford University Press).

Waldron, Jeremy (2002): God, Locke, and Equality. Christian Foundations of John Locke's Political Thought (New York, Cambridge University Press). 